\title{
Studies of thermally assisted interactions of polysulphide polymer with ionic liquids
}

\author{
NANDKISHOR B SHIRSATH ${ }^{1}$, GAURAV R GUPTA ${ }^{1}$, VIKAS V GITE ${ }^{1}$ and \\ JYOTSNA S MESHRAM ${ }^{1,2, *}$ \\ ${ }^{1}$ School of Chemical Sciences, North Maharashtra University, Jalgaon 425 001, India \\ ${ }^{2}$ Department of Chemistry, Rashtrasant Tukadoji Maharaj Nagpur University, Nagpur 440 033, India \\ *Author for correspondence (drjsmeshram@gmail.com)
}

MS received 23 February 2017; accepted 1 August 2017; published online 6 April 2018

\begin{abstract}
The present paper, for the first time, reports analysis regarding the structural interactions of polysulphide polymer with ionic liquids (ILs), which have been studied by thermo-gravimetry analysis (TGA). A systematic thermal analysis of polysulphide polymer has been carried out, based on polymerization and series of ILs like tetrabutyl ammonium hexa-fluorophosphate [TBA] $\left[\mathrm{PF}_{6}\right], \mathrm{N}$-butylpyridinium bromide [Bpy] $[\mathrm{Br}]$ and 1-butyl-3-methyl imidazolium bromide $[\mathrm{Bmim}][\mathrm{Br}]$ using a thermal gravimetry analyser. The plausible mechanism of the interactions and thermally induced reactions of polysulphide polymer with ILs has been advanced and discussed. The probable interactions of polysulphide polymer with $[\mathrm{Bmim}][\mathrm{Br}]$ and $[\mathrm{TBA}]\left[\mathrm{PF}_{6}\right]$ are also discussed. The interactions between polysulphide polymer and ILs were confirmed by Fourier transform-infrared spectroscopy, TGA-differential thermo-gravimetry analysis and field emission scanning electron microscopy analysis.
\end{abstract}

Keywords. Polysulphide polymer; $\left[\mathrm{TBA}^{\mathrm{B}}\right]\left[\mathrm{PF}_{6}\right]$; $[\mathrm{Bmim}][\mathrm{Br}]$; TGA-DTA; polymerization.

\section{Introduction}

John and Amulya [1] pioneered the synthesis of organic fused salt, N-butylpyridinium chloride, as an electrolyte. Subsequently, Wilkes, one of the co-worker of Osteryoung, performed a systematic study on 1,3-dialkylimidazolium salts and classified ionic liquids (ILs) from molten salts on the basis of their melting temperature. To date, the huge literature cited on ILs accentuates the importance of these salts in the field of materials [2-10]. ILs belong to a class of organic solvents with high polarity and a pre-organized solvent structure, and are categorized as supramolecular solvents after water [11]. The structural interactions present in the ILs are responsible for their low volatility, high thermal stability $[12,13]$ and their outstanding behaviour in solution or in vapour phases $[14,15]$.

Waring [16] emphasized the role of sulphur and sulphurcontaining compounds, from the perspective of life-related processes. Sulphur-sulphur bonds are the backbone of biochemistry, which are responsible for a large number of life-prevailing processes in living organisms. Commonly they are engaged in the maintenance of protein shape and function, as in keratin. Disulphide groups have a comparable set of properties as they can hold the whole molecule in a fixed conformation. In the modern world of materials, composite materials containing unsaturated elastomers and oligomers are the most popular components for sealing and waterproofing materials. Today, sealing materials based on reactive oligomers have attracted the attention of researchers, scientists and industrialists. Polysulphide oligomer sealants (PSOs), with polysulphide as the main representative, occupy a special place among these materials [17]. Thiokol was the first synthetic elastomer synthesized by Patrick in 1920; however, these solvent-resistant elastomers have limited use because of their foul odour [18]. They can be reduced to liquid polymers that can be re-oxidized to solid elastomers used in caulking materials and some rocket propellant formulations.

Lithium/sulphur batteries have great potential as the next generation of high-energy rechargeable lithium batteries because of their inimitable structure-related properties [19, 20]. Although, these materials are very labile towards alkali metals, transition metals and various organic cross-linkers, they give precious self-healing composition of polysulphide polymers, [21] an effective catalytic system for organic transformations [22] and polysulphide polymer sealants [23]. However, before implementation, it is essential to understand the efficiency and efficacy of these valuable materials, particularly their thermal response profiles.

Thermal methods of analysis are well-defined techniques in which physical and chemical changes related to the substance under investigation can been determined as a function of an externally applied and programmed temperature [24]. Nowadays, thermal methods play vital roles in the characterization of materials [25]. They neatly focus on the physicochemical processes when matter is subjected to thermal action involving weight changes, crystalline transitions, mechanical 
properties, enthalpy, magnetic susceptibility, optical properties, acoustic properties, etc. Thermal techniques follow such changes, generally as a function of temperature that could extend from sub-zero to elevated temperatures. Thermal analysis techniques have been employed to study various types of commercially as well as academically precious inorganic and organic construction materials. These methods have been applied more extensively to extract subtle information about the materials, viz., kinetics of reactions, mechanisms, quality control of raw materials, rheological changes, glass transitions and causes leading to the deterioration of materials [26-29]. Besides these, thermal techniques are also used in combination with other techniques such as chemical analysis, X-ray diffraction, Fourier transform-infrared (FT-IR) analysis and scanning electron microscopy (SEM), which provide new dimensions to the characterization of compounds using modern analytical instrumentations.

Khawam and Flanagan [30], in their review article, made assumptions and mathematically derived the most commonly used reaction models in solid-state kinetics as they have a theoretical physical meaning and are not merely based on goodness of data fits to complex mathematical expressions, in order to convert thermal data to valuable kinetic database including energy of activation and frequency factor.

The study reveals that the ILs could be used in the field of sealants, where they engage in the structural interactions with polysulphide polymers. The implications of these findings are discussed in terms of cross-linking interactions within polysulphide polymer molecules and ILs influenced by thermal energy effects, FT-IR and SEM analysis. An attempt has been made to understand the non-isothermal kinetics of decomposition of polysulphide polymer and polysulphide polymer in ILs using the methodology developed by Coats and Redfern. The values of energy of activation and frequency factor are calculated and discussed in the present study, which elegantly establishes the mechanism for stabilization of polysulphide polymer in ILs.

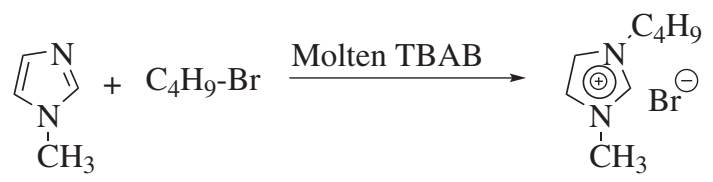

Scheme 1. Synthesis of 1-butyl-3-methyl-imidazolium bromide.

\section{Experimental}

\subsection{Materials and methods}

2.1a Materials: The materials used in this experiment included sulphur, 1,2-dibromoethane, tetra-butyl-ammonium bromide, n-butyl bromide and $\mathrm{NaOH}$ of analytical grade purchased from S D Fine Chemicals Ltd., Mumbai, India; 1-methyl-imidazole was purchased from Sigma Aldrich and used as it was without any purification.

The details regarding synthesis, instrumentation and characterization of ILs and polysulphide polymer are given below.

2.1b Procedure for the synthesis of 1-butyl-3-methylimidazolium bromide: Solutions of 1-methyl-imidazole (30 mmol) and n-butyl bromide (30 mmol) were gradually added to molten tetra-butyl-ammonium bromide $(30 \mathrm{mmol})$ [30]. [Caution: alkyl halide is volatile in nature; to avoid explosion, make additions in portions through a water condenser]. After addition, the reaction mixture was cooled to room temperature and ethyl-methyl ketone was added into the resultant mixture. The two layers obtained were separated; the product was collected after washing with excess ethyl-methyl ketone and transferred to a vacuum oven for drying (scheme 1).

\section{1c Procedure for the synthesis of tetra-butyl-ammonium} hexa-fluorophosphate: A saturated solution of potassium hexa-fluorophosphate in water was slowly added to saturated solution of [TBA] $[\mathrm{Br}]$ with constant stirring [31]. The white solid of $\left[\mathrm{TBA}^{\mathrm{B}}\right]\left[\mathrm{PF}_{6}\right]$ was separated out and filtered using a pump (scheme 2).

2.1d Procedure for the synthesis of polysulphide polymer: Preparation of sodium polysulphide Sodium hydroxide $(1.5 \mathrm{~g})$ was dissolved in distilled water $(10 \mathrm{ml})$ [32]. A gradual addition of powdered sulphur was carried out in a warm solution of sodium hydroxide to form a clear solution of deep red coloured sodium polysulphide (scheme 3 ).

Preparation of polysulphide polymer To the round bottom flask containing sodium polysulphide solution, 1,2dibromoethane was added with constant stirring [33]. The reaction mixture was stirred until white lumps of the polymeric product were separated out. The product was collected after washing with excess of water (scheme 4).

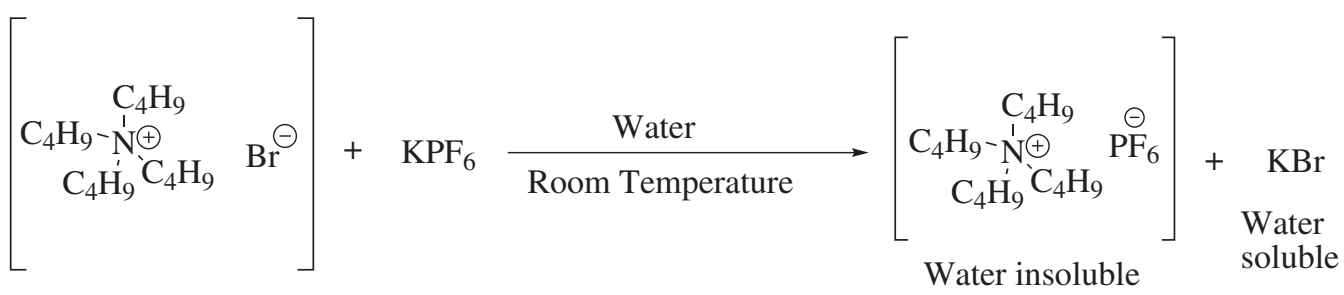

Scheme 2. An anion metathesis for the formation of tetra-butylammoniumhexa-fluorophosphate. 


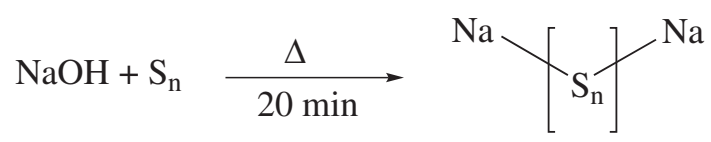

Scheme 3. Preparation of sodium polysulphide.

2.1e Polysulphide polymer in ILs: A two-necked round bottom flask was charged with ILs ([Bmim][Br] or $[\mathrm{TBA}]\left[\mathrm{PF}_{6}\right]$ ) and polysulphide polymer (ratio 2:1). The flask was equipped with a thermometer and a reflux condenser. The reaction mixture was heated at $353 \mathrm{~K}$ for 30 min under atmospheric pressure conditions. The contents of reaction mixture were allowed to cool at room temperature. Immediately, a deep-brown gel-like product was formed. The product was analysed by thermo-gravimetry analysis (TGA) and the results are summarized in table 1.

\subsection{Analytical methods}

2.2a FT-IR analysis of polysulphide polymer: FT-IR analysis of polysulphide polymer was performed on an FT-IR affinity model of Shimadzu. Dry $\mathrm{KBr}$ was used to set the background; thereafter, a $\mathrm{KBr}$ pellet was developed and analysed. Prior to the analysis, the instrument was calibrated by performing an IR scan of polystyrene film.

2.2b TGA-differential thermo-gravimetry analysis: The TGA-differential thermo-gravimetry analysis (DTA) of the synthesized ILs and polysulphide polymer as well as polysulphide polymer in ILs was performed on a PerkinElmer 4000 instrument, with cryostat assembly, which was kept in an air-conditioned lab having humidity of $5-10 \%$. Samples having weights in the range of 4-10 mg were used for the measurements, and subjected to nitrogen purging at a flow rate of $20 \mathrm{ml} \mathrm{min}^{-1}$. The heating rate of the sample was always kept at $10 \mathrm{~K} \mathrm{~min}^{-1}$. Thus, after establishing the good working of the instrument, our samples of ILs as well as synthesized polysulphide polymer were subjected to heat measurement. 2.2c Microscopic morphology analysis: SEM analyses of polysulphide polymer and the same in ILs sample were performed on a SEM, S-4800, JEOL, JSM 6360 \& JSM 5400 instrument in the voltage range of $0.5-30 \mathrm{kV}$ by the sample drop cast method.

\section{Results and discussion}

A systematic scrutiny of table 1 reveals that polysulphide polymer is insoluble (unfavourable for interactions with ILs) in $[\mathrm{Bpy}][\mathrm{Br}]$ on heating, which is attributed to the physicochemical nature of $[\mathrm{Bpy}][\mathrm{Br}]$. The compound has different freezing and melting points and as a result the compound is found in gel-like state [14]. However, it is soluble (favourable interactions with ILs) in $[\mathrm{Bmim}][\mathrm{Br}]$ and $[\mathrm{TBA}]\left[\mathrm{PF}_{6}\right]$ on heating and the results are discussed later.

\subsection{FT-IR analysis of polysulphide polymer and the same in ILs}

FT-IR spectrum (figure 1) of polysulphide polymer reveals there is no broadness over $3000 \mathrm{~cm}^{-1}$ that indicates absence of water molecule in the synthesized polysulphide polymer. Catenation is a unique chemical characteristic of sulphur, where the formation of $\mathrm{S}-\mathrm{S}$ bonds in extended chains is common, and has characteristic intense peaks at 500 and $450 \mathrm{~cm}^{-1}$ due to $\mathrm{S}-\mathrm{S}$ stretch in polysulphide polymer [34]. In addition, $\mathrm{C}-\mathrm{S}$ stretching of sulphides is observed in the range of $700-590 \mathrm{~cm}^{-1}$ [35]. In experimental studies on the closer examination of FT-IR spectrum of the synthesized polysulphide polymer, it revealed a sharp peak at $676 \mathrm{~cm}^{-1}$ representing $\mathrm{C}-\mathrm{S}$ stretching.

The loosely held electrons in the outermost orbital's of the sulphur atoms confer certain 'flexibility' to the electronic configuration, increasing the possibility of reactions with other sulphur-containing molecules, which are responsible for the formation of large polymeric structures of sulphur.

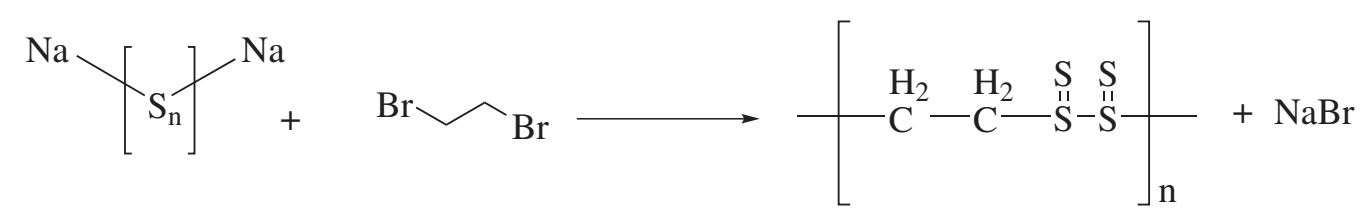

Scheme 4. Synthesis of polysulphide polymer.

Table 1. Experimental conditions for polysulphide polymer in ILs.

\begin{tabular}{lcccc}
\hline Entry & Temperature $(\mathrm{K})$ & Time $(\mathrm{min})$ & Ionic liquid & Product \\
\hline A & 353 & 30 & {$[\mathrm{Bmim}][\mathrm{Br}]$} & Deep-brown gel \\
B & 353 & 30 & {$[\mathrm{TBA}][\mathrm{PF} 6]$} & $\begin{array}{c}\text { Deep-brown gel } \\
\text { White polymer + IL }\end{array}$ \\
$\mathrm{D}$ & $353-383$ & $60-80$ & {$[\mathrm{Bpy}][\mathrm{Br}]$} & .
\end{tabular}

[Bpy][Br]: N-n-butyl-pyridinium bromide. 


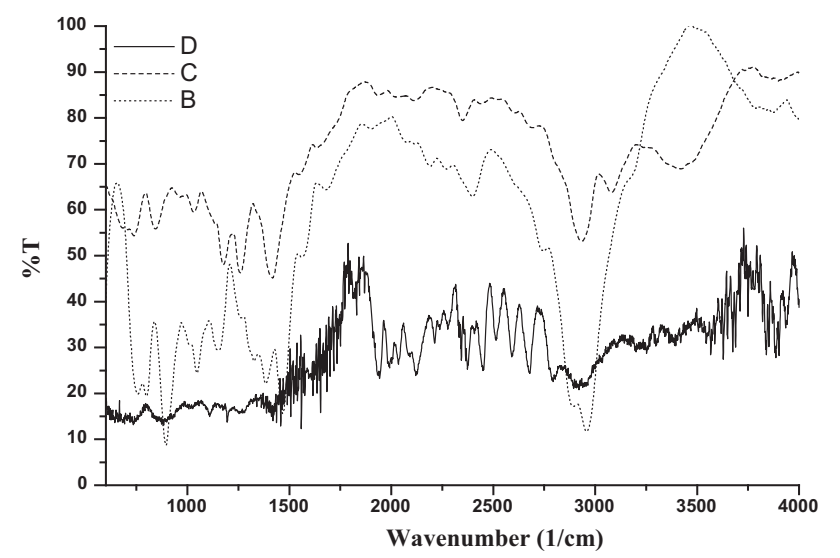

Figure 1. FT-IR spectra of D: polysulphide polymer, C: polysulphide polymer in $[\mathrm{Bmim}][\mathrm{Br}], \mathrm{B}$ : polysulphide polymer in [TBA][PF6].

These polymeric forms have been engaged in a series of inter-conversions including breaking and remaking the sulphur bonds to form hetero-dimers with other molecules often via reduction to thiols $(-\mathrm{SH})[16]$.

\subsection{Morphological analysis of polysulphide polymer and same in ILs}

Morphological studies of polysulphide polymer and the same in ILs (figure 2) revealed flower-like structure of polysulphide polymer. On other hand, in ILs the structure-breaking interactions with polysulphide polymer were found, which are attributed to the high-dielectric medium and thermal stability provided by IL (particularly $[\mathrm{TBA}]\left[\mathrm{PF}_{6}\right]$ ). The surface analysis of the polysulphide polymer in [Bmim] $[\mathrm{Br}]$ gives surprising results, i.e., whole structure of polysulphide polymer collapses.

\subsection{TGA-DTA of polysulphide polymer and same in ILs}

Generally, polysulphide polymers have very bad resistance to high temperatures and soften at $343 \mathrm{~K}$.

The thermogram of the synthesized polysulphide polymer (figure 3) is found to be in agreement with those reported in the literature [36]. Besides, thermal profile of the polysulphide polymer elucidates the decomposition procedure of the polysulphide polymer, which has a two-step mechanism. Firstly, a slow decomposition is observed in the range of 343-513 K, and secondly a very rapid decomposition is observed over $513 \mathrm{~K}$ and completed at $573 \mathrm{~K}$. The $\%$ weight loss observed between 513 and $573 \mathrm{~K}$ is $85.377 \%$. The probable reason behind the weight loss is the skeletal breakdown of the polysulphide polymer. The plausible mechanism for thermally induced degradation of polysulphide polymer is shown in scheme 5, which consists of the formation of cyclo-sulphur analogue and acetylene.
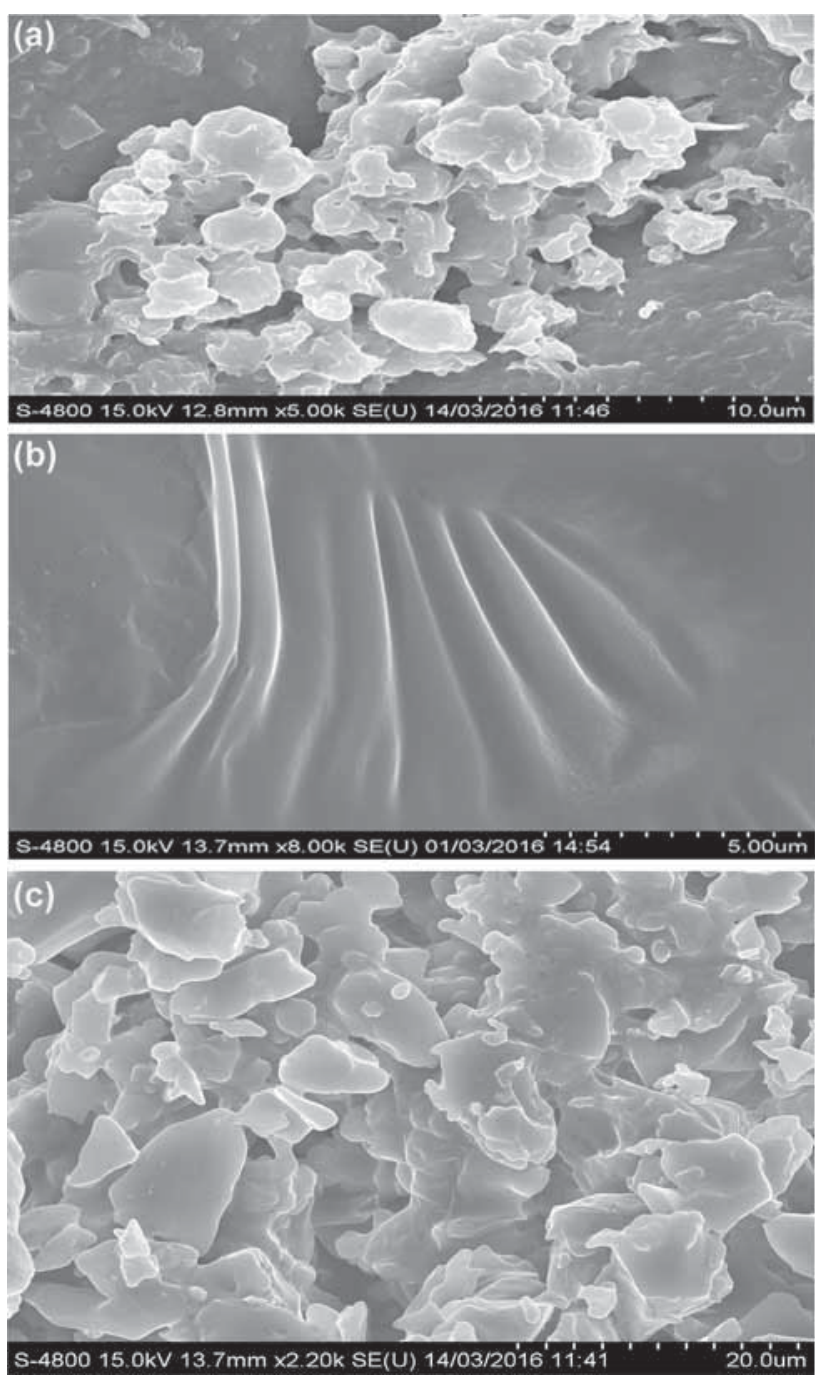

Figure 2. SEM analysis of (a) polysulphide polymer, (b) polysulphide polymer in $[\mathrm{bmim}][\mathrm{Br}]$ and (c) polysulphide polymer in [TBA][PF6].

\subsection{Polysulphide polymer in 1-butyl-3-methyl imidazolium bromide}

The interactions between the IL ions and sulphur solutes lead to the formation of inclusion complexes [37]. ILs have thermally stable composition of ions; the thermogram (figure 4a) of pure $[\mathrm{Bmim}][\mathrm{Br}]$ manifests that the liquid releases water molecule up to $373 \mathrm{~K}$ and the measurable weight loss found at $373 \mathrm{~K}$ is $11.272 \%$, which indicates that 7.05 water molecules are associated with $[\mathrm{Bmim}][\mathrm{Br}]$ and the correct structural formula for the IL is $[\mathrm{Bmim}][\mathrm{Br}] \cdot 7 \mathrm{H}_{2} \mathrm{O}$. Though $[\mathrm{Bmim}][\mathrm{Br}]$ is quite stable over $533 \mathrm{~K}$, all the stacking interactions of [Bmim][Br] collapse over $533 \mathrm{~K}$, and the IL starts decomposing. As a result of the decomposition, $88.033 \%$ weight loss is found in the temperature range of $533-573 \mathrm{~K}$.

The thermal profile of the polysulphide polymer in $[\mathrm{Bmim}][\mathrm{Br}]$ (figure $4 \mathrm{~b}$ ) gives valuable information regarding the structural change observed in polysulphide polymer, 
like softening of the polysulphide polymer over $313 \mathrm{~K}$, leading towards decomposition after softening. The weight loss found between temperatures 313 and $493 \mathrm{~K}, 7.893 \%$, may be due to the loss of water molecule associated with ILs $[\mathrm{Bmim}][\mathrm{Br}]$. The structural interactions between [Bmim][Br] and polysulphide polymer provide extra stability to the polysulphide polymer as seen in the thermogram (figure $4 \mathrm{~b}$ ). The weight loss found in the temperature interval from 533 to $583 \mathrm{~K}$ is about $89.932 \%$. The weight loss found is reasonably higher than that of pure polysulphide polymer and this situation evidences the mechanism of interactions between an IL [Bmim] $[\mathrm{Br}]$ and a polysulphide polymer.

A plausible mechanism for the thermally induced interactions between [Bmim] $[\mathrm{Br}]$ and polysulphide polymer (scheme 6) causes a new bond formation between sulphur and bromine, accompanied with an electrostatic interaction between a cationic part of IL, i.e., [Bmim] along with the sulphur atom.

\subsection{Polysulphide polymer in tetra-butyl-ammonium hexa-fluorophosphate}

Thermal response of $\left[\mathrm{TBA}^{\mathrm{B}}\right]\left[\mathrm{PF}_{6}\right]$ is quite interesting and has three stages of decomposition (figure 5a). The decomposition of $[\mathrm{TBA}]\left[\mathrm{PF}_{6}\right]$ is initiated at $326 \mathrm{~K}$; later a second inflection is found at $507 \mathrm{~K}$ and finally it decomposes completely at

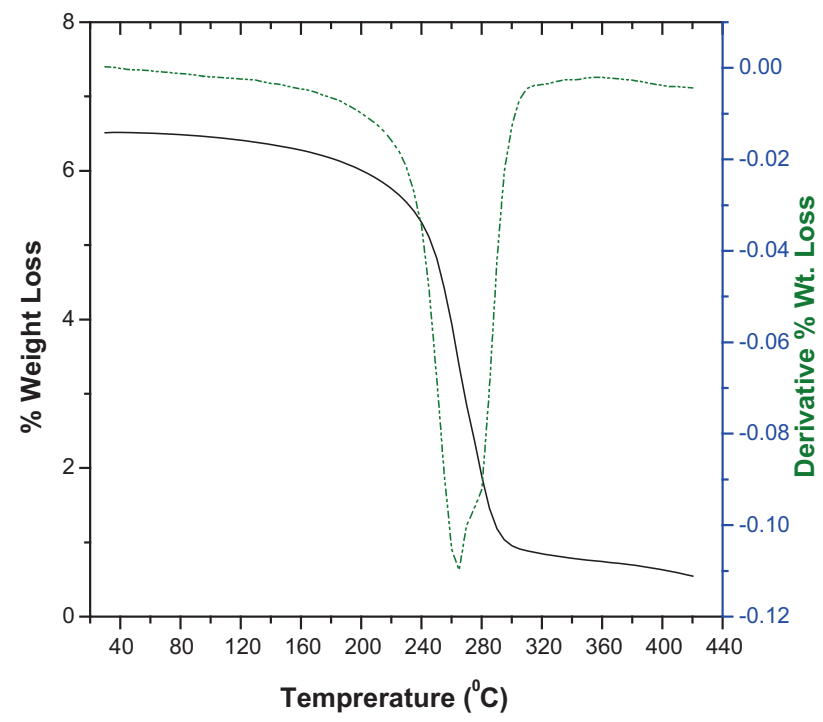

Figure 3. TGA-DTA of polysulphide polymer.
$663 \mathrm{~K}$ with weight loss of $21.50,4.591$ and $74.47 \%$, respectively. $[\mathrm{TBA}]\left[\mathrm{PF}_{6}\right]$ has a stable gel-like structure in the region of $326-507 \mathrm{~K}$.

Thermal profile of polysulphide polymer in $\left[\mathrm{TBA}^{\mathrm{B}}\right]\left[\mathrm{PF}_{6}\right]$ (figure 5b) provides information regarding interactions between $[\mathrm{TBA}]\left[\mathrm{PF}_{6}\right]$ and polysulphide polymer. These interactions are responsible for early degradation of the polysulphide polymer. The summation of the weight loss of the three decomposition steps in the case of polysulphide polymer in $\left[\mathrm{TBA}^{2}\left[\mathrm{PF}_{6}\right](83.10 \%)\right.$ is low as compared with the decomposition of pure polysulphide polymer (86.38\%). A plausible mechanism is proposed for the thermally induced
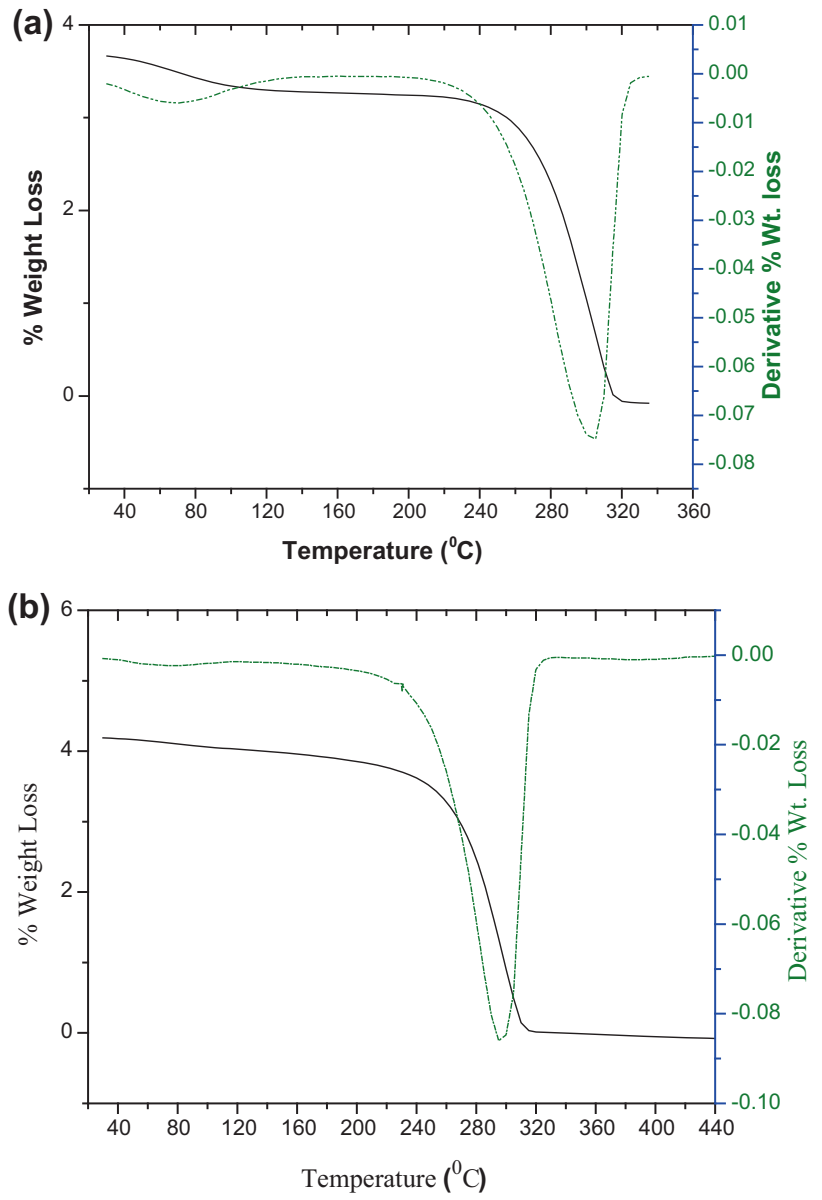

Figure 4. TGA-DTA of (a) pure $[\mathrm{Bmim}][\mathrm{Br}]$ and (b) polysulphide polymer in $[\mathrm{Bmim}][\mathrm{Br}]$.

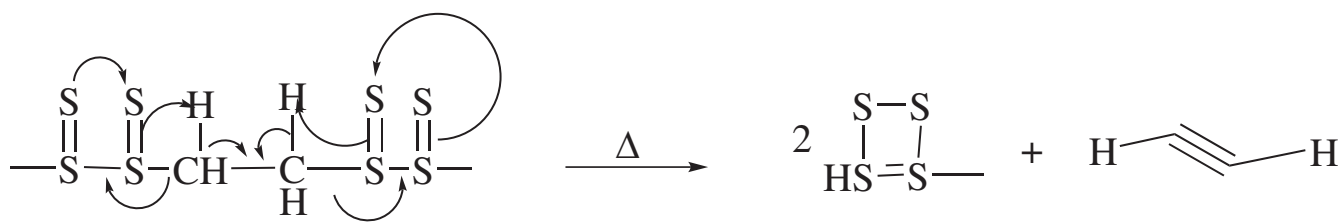

Scheme 5. Plausible mechanism for the degradation of polysulphide polymer. 


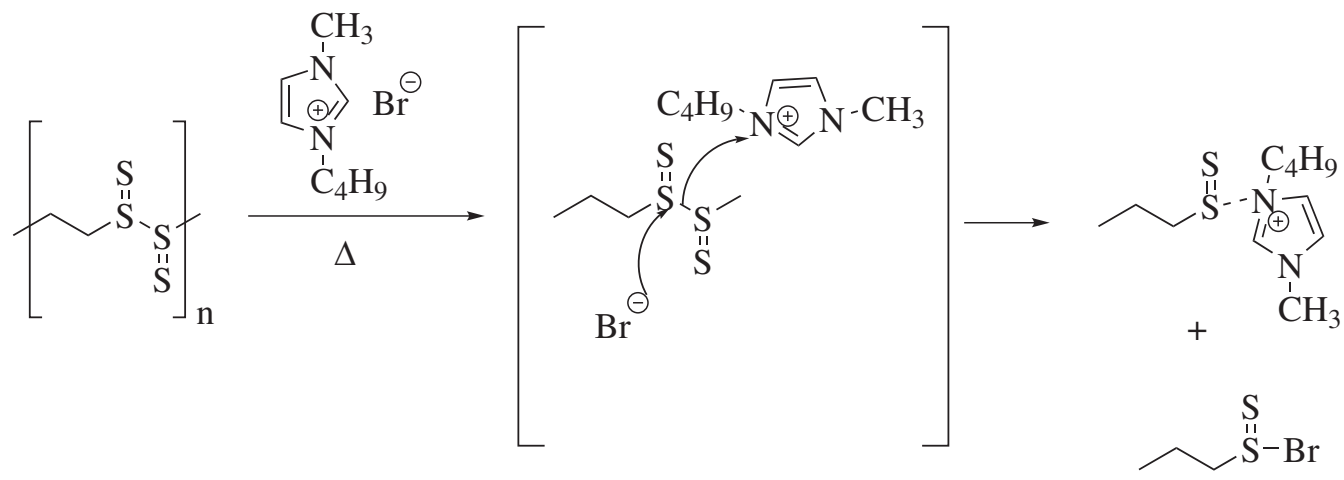

Scheme 6. Probable interactions of polysulphide polymer with $[\mathrm{Bmim}][\mathrm{Br}]$.
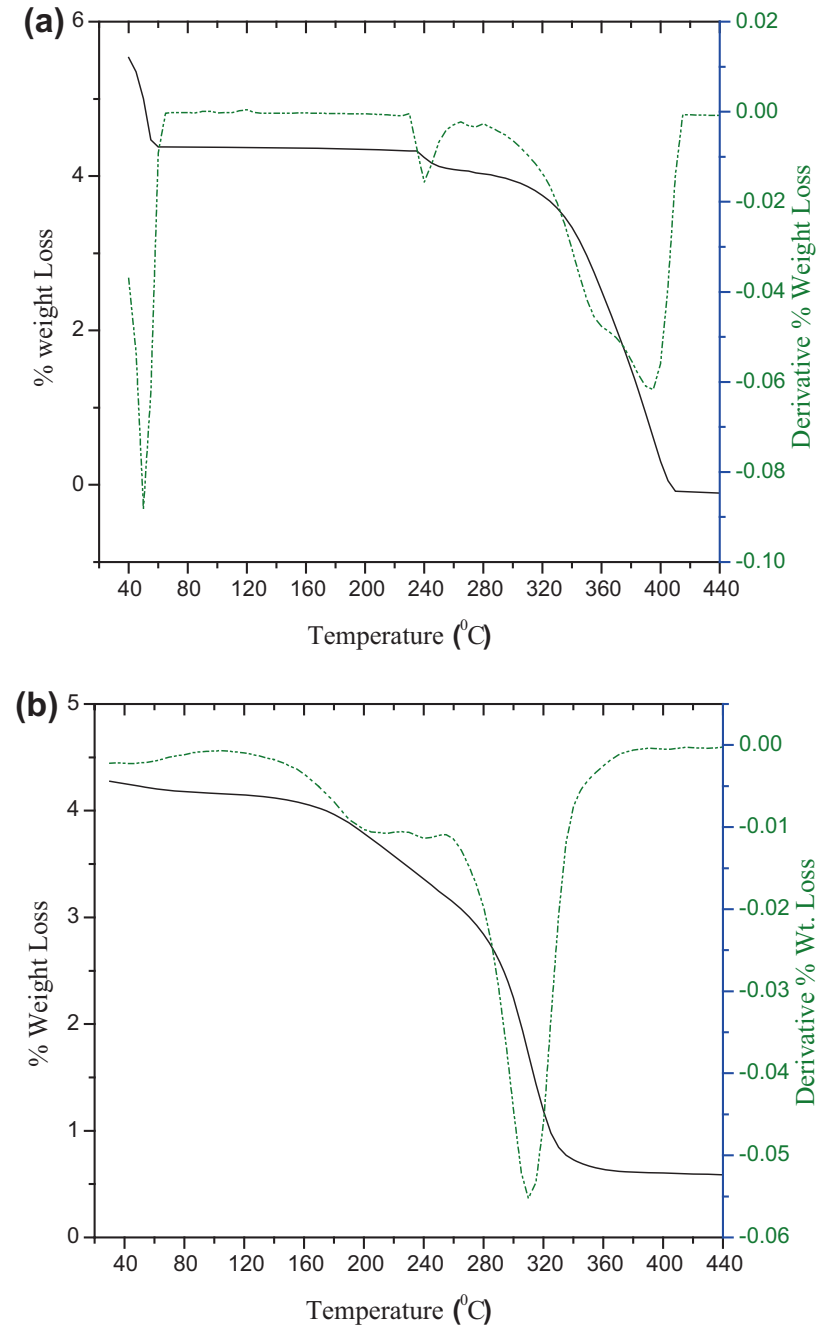

Figure 5. TGA-DTA of (a) pure $[\mathrm{TBA}]\left[\mathrm{PF}_{6}\right]$ and (b) polysulphide polymer in $[\mathrm{TBA}]\left[\mathrm{PF}_{6}\right]$.

interactions between $[\mathrm{TBA}]\left[\mathrm{PF}_{6}\right]$ and polysulphide polymer (scheme 7).
The mechanism starts with the disproportionation of $\mathrm{PF}_{6}$ into fluoride anion and $\mathrm{PF}_{5}$ as shown [38]:

$$
[\mathrm{TBA}]\left[\mathrm{PF}_{6}\right] \longrightarrow[\mathrm{TBA}] \mathrm{F}^{-}+\left[\mathrm{PF}_{5}\right]
$$

A nucleophilic attack of a fluoride ion on sulphur is responsible for the formation of a new bond between sulphur and fluorine. Furthermore, there is a possibility of an electrostatic interaction between a positive part of ILs, i.e., [TBA], and the sulphur atom [39-42].

The peak temperature of pure polysulphide polymer shown in DTA (figure 3) is about $538 \mathrm{~K}$, while the interactions of polysulphide polymer with [Bmim][Br] (figure $4 \mathrm{~b}$ ) and [TBA] $\left[\mathrm{PF}_{6}\right]$ (figure 5b) are responsible for the shift of peak temperature to higher values 573 and $583 \mathrm{~K}$, respectively. The increases in peak temperature for polysulphide polymer in $[\mathrm{Bmim}][\mathrm{Br}]$, and in $\left[\mathrm{TBA}^{\mathrm{B}}\left[\mathrm{PF}_{6}\right]\right.$ are evident from the interaction between polysulphide polymer and $[\mathrm{Bmim}][\mathrm{Br}]$, and $[\mathrm{TBA}]\left[\mathrm{PF}_{6}\right]$.

\subsection{Non-isothermal kinetics}

The use of TGA data to evaluate energy of activation and frequency factor has been investigated by a number of researchers [39-42]. The Coats and Redfern [43] method to retrieve kinetic parameters has been tested with numerical integration applied to a first-order irreversible reaction using equations (1) and (2):

$$
\begin{aligned}
\log _{10}\left[\frac{1-(1-\alpha)^{1-n}}{T^{2}(1-n)}\right]= & \log _{10} \frac{A R}{\alpha E}\left[1-\frac{2 R T}{E}\right] \\
& -\left[\frac{E}{2.303 R T}\right], \\
\log _{10}\left[-\log _{10} \frac{(1-\alpha)}{T^{2}}\right]= & \log _{10} \frac{A R}{\alpha E}\left[1-\frac{2 R T}{E}\right] \\
& -\left[\frac{E}{2.303 R T}\right],
\end{aligned}
$$



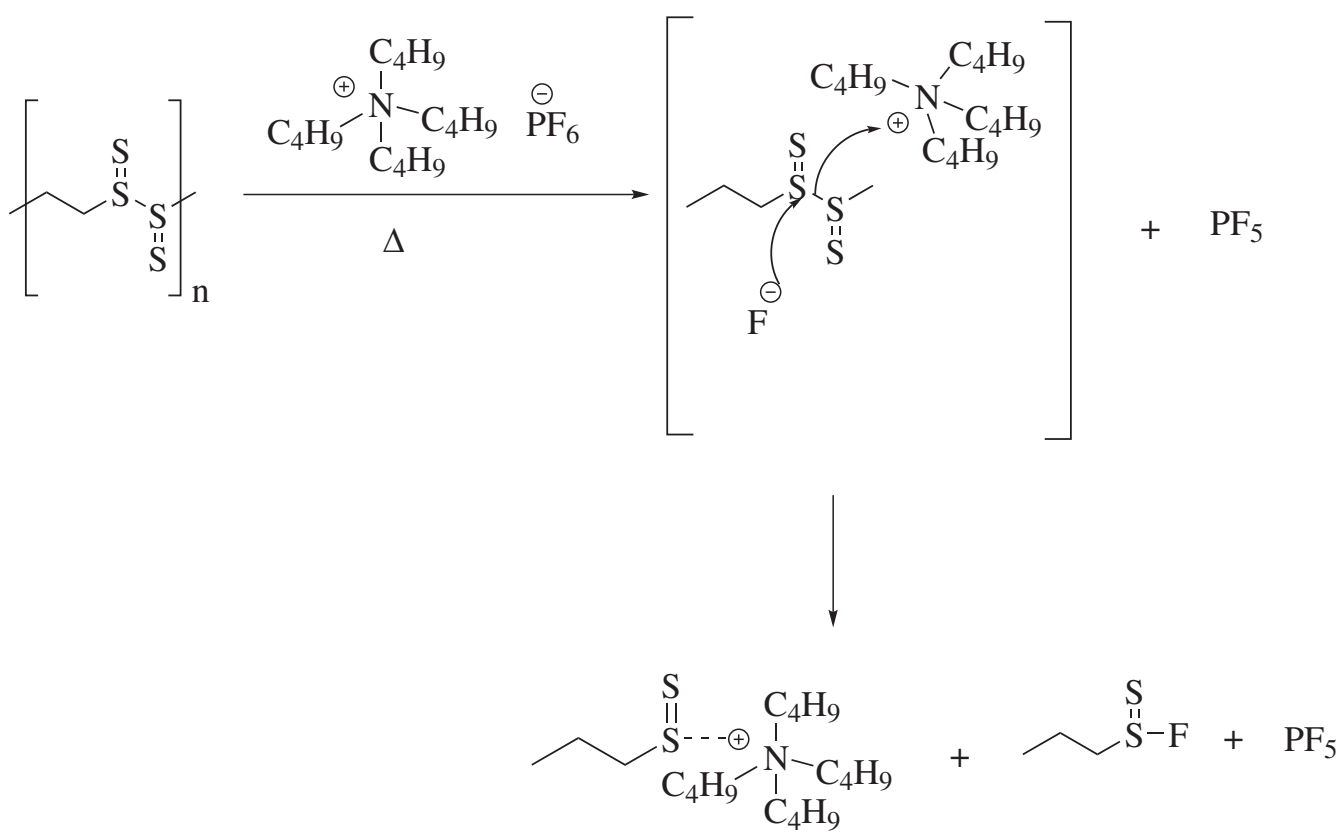

Scheme 7. Probable interactions of polysulphide polymer with $\left[\mathrm{TBA}^{\mathrm{B}}\right]\left[\mathrm{PF}_{6}\right]$.

Table 2. Energy of activation and frequency factor values calculated by the Coats-Redfern method.

\begin{tabular}{lcccc}
\hline Entry & $n$ & Energy of activation $\left(\mathrm{kJ} \mathrm{mol}^{-1}\right)$ & Frequency factor & $R^{2}$ \\
\hline Thiokol & & & \\
A & 0 & 26.83 & $3.76 \mathrm{E}-04$ & 0.9957 \\
B & 0.5 & 19.93 & $1.31 \mathrm{E}-04$ & 0.9952 \\
C & 1 & 0.86 & 6.71 & 0.9923 \\
Thiokol in $[\mathrm{Bmim}][\mathrm{Br}]$ & & & \\
D 0 & 70.54 & 6.27 & 0.9971 \\
E 0.5 & 54.60 & 0.29 & 0.9969 \\
Thiokol in $[\mathrm{TBA}]\left[\mathrm{PF}_{6}\right]$ & & & \\
F & 0 & 23.47 & $2.29 \mathrm{E}-04$ & 0.9890 \\
G 0.5 & 17.17 & $8.66 \mathrm{E}-05$ & 0.9864 \\
\hline
\end{tabular}

where $\alpha=W_{0}-W_{\mathrm{i}} / W_{0}-W_{\mathrm{f}}, W_{0}$ is the initial weight, $W_{\mathrm{i}}$ is the weight at initiation of decomposition reaction and $W_{\mathrm{f}}$ the final weight at residue temperature $T, R$ the gas constant and $n$ the order of reaction. The values of energy of activation $\left(E_{\mathrm{a}}\right)$ and frequency factor $(A)$ obtained by equation $(1)$ (for $n \neq 1)$ and equation (2) (for $n=1$ ), for the decomposition of polysulphide polymer, polysulphide polymer with [Bmim][Br] and polysulphide polymer with $\left[\mathrm{TBA}^{-}\left[\mathrm{PF}_{6}\right]\right.$ are summarized in table 2. The data of $\log _{10}\left[-\log _{10} \frac{(1-\alpha)}{T^{2}}\right]$ against $1 / T$ is best fitted with a value of $n$ (order of reaction) $=0$ and $1 / 2$.

It is difficult to account for zero or fractional $(0,1 / 2)$ order of reaction. Closer scrutiny of table 2 enlightens that the energy of activation is higher when $n=0$, for polysulphide polymer, polysulphide polymer in $[\mathrm{Bmim}][\mathrm{Br}]$ and polysulphide polymer in $[\mathrm{TBA}]\left[\mathrm{PF}_{6}\right]$.

\section{Conclusion}

The present study has efficiently emphasized the use of ILs in stabilizing the polysulphide polymer, which has enormous application as a sealant, water resistant and also in aero-space applications. IL $[\mathrm{Bmim}][\mathrm{Br}]$ is successfully stabilized by the polysulphide polymer; however, thermal lability of $[\mathrm{TBA}]\left[\mathrm{PF}_{6}\right]$ causes two-step thermal decomposition shown in TGA-DTA for the composition of polysulphide polymer in $[\mathrm{TBA}]\left[\mathrm{PF}_{6}\right]$. Morphological studies of the polysulphide polymer and polysulphide polymer in ILs clearly indicate active involvement of ILs in the structure of polysulphide polymer. The study has opened up new horizons for the use of ILs in the field of sealants as a stabilizer. 


\section{Acknowledgements}

We acknowledge the School of Chemical Sciences, North Maharashtra University, Jalgaon, and Shri G H Raisoni Doctoral Fellowship for financial support.

\section{References}

[1] John O M and Amulya K N R 1998 Ionics in: Modern electrochemistry vol 1 (New York: Kluwer Academic/Plenum Publishers) p 19

[2] Gupta G, Chaudhari G, Tomar P, Gaikwad Y, Azad R, Pandya $\mathrm{G}$ et al 2012 Chem. Eur. J. 3475

[3] Tomar P A, Yadav S M and Gupta G R 2014 Polym. Bull. 71 1349

[4] Cao Y, Zhang J, Bai Y, Li R, Zakeeruddin S M, Grätzel M et al 2008 J. Phys. Chem. C 11213775

[5] Brennan L J, Barwich S T, Satti A, Faure A and Gun'ko Y K 2013 J. Mater. Chem. A 18379

[6] Gorlov M and Kloo L 2008 Dalton Trans. 202655

[7] Kawano R, Matsui H, Matsuyama C, Sato A, Susan M A B H, Tanabe N et al 2004 J. Photochem. Photobiol. 16487

[8] He Z and Alexandridis P 2015 Phys. Chem. Chem. Phys. 17 18238

[9] Cassity C G, Mirjafari A, Mobarrez N, Strickland K J, O’Brien R A and Davis J H 2013 Chem. Commun. 497590

[10] Swatloski R P, Spear S K, Holbrey J D and Rogers R D 2002 J. Am. Chem. Soc. 1244974

[11] Markus A K, Daibin S and Bernd Z Yong 2004 Angew. Chem. Int. Ed. $\mathbf{4 3} 4988$

[12] Reichert W M, Holbrey J D, Vigour K B, Morgan T D, Broker G A and Rogers R D 2006 Chem. Commun. 464767

[13] Shirsath N B, Gite V V and Meshram J S 2016 Russ. J. Appl. Chem. 891893

[14] Shaikh V R, Terdale S S, Gupta G R, Hundiwale D G and Patil K J 2013 J. Mol. Liq. 18614

[15] Gupta G R, Chaudhari G R and Tomar P A 2011 Asian J. Chem. 258261

[16] Waring R H 1996 in: S Mitchell (ed) Biological interactions of sulfur compound (Cornwall: Taylor and Francis Ltd.) p 145

[17] Yuri N K, Vladimir S M and Timur R D 2015 Polysulfide oligomer sealants synthesis, properties, and applications (Canada: Apple Academic Press Inc) p XVII

[18] Charles E C 2013 Introduction to polymer chemistry, 3rd ed (London: Taylor and Francis Group CRC Press) p 200

[19] Duan B, Wang W, Wang A, Yuan K, Yu Z, Zhao H et al 2013 J. Mater. Chem. A 113261
[20] Ahn W, Lim S N, Lee D U, Kim K B, Chen Z and Yeon S H 2015 J. Mater. Chem. A 39461

[21] Lafont U, Van Zeijl H and Van Der Zwaag S 2012 ACS Appl. Mater. Interfaces 46280

[22] Greenwood N N and Earnshaw A 1984 Chemistry of the element (Tarrytown, New York: Pergamon Press) p 1542

[23] Kurbangaleeva A R, Kurkin A I and Khakimullin Y N 2012 Russ. J. Appl. Chem. 85432

[24] Harry G B and Richard D B 2006 in: S Ahuja and N Jespersen (eds) Comprehensive analytical chemistry (UK: Elsevier B.V.) p 63

[25] Ramachandran V S, Paroli R M, Beaudoin J J and Delgado A H 2002 Handbook of thermal analysis of construction materials (US: William Andrew)

[26] Simon P (ed) 2012 Thermal analysis of micro-, nano- and noncrystalline materials: transformation, crystallization, kinetics and thermodynamics vol 9 (New York: Springer Science \& Business Media)

[27] Bernhard W 2005 Thermal analysis of polymeric materials (Berlin-Heidelberg: Springer-Verlag) p V

[28] Robert F S 1994 Thermal analysis of materials (New York: Marcel Dekker, Inc) p 111

[29] Hatakeyama T and Quinn F X 1999 Thermal analysis: fundamentals and applications to polymer science (Chichester, UK: John Willey \& Sons Ltd)

[30] Khawam A and Flanagan D R 2006 J. Phys. Chem. B 110 17315

[31] Gupta G R, Chaudhari G R, Tomar P A, Waghulade G P and Singh K 2012 Asian J. Chem. 244675

[32] Sasson Y and Neumann R 1997 Handbook of phase transfer catalysis (London, UK: Chapman \& Hall)

[33] Baker E M 1943 J. Chem. Educ. 20427

[34] Coates J 2000 in: R A Meyers (ed) Encyclopedia of analytical chemistry (Chichester: John Wiley \& Sons Ltd)

[35] Barbara S 1997 in: J A David (ed) Biological applications of infrared spectroscopy (Chichester: John Wiley and Sons Ltd) p 65

[36] Roff W J and Scott J R 1971 Fibres, films, plastics and rubbers: a handbook of common polymers (London and Prescot: Elsevier)

[37] Holbrey J D, López-Martin I, Rothenberg G, Seddon K R, Silvero G and Zheng X 2008 Green Chem. 1087

[38] Farooq O 1997 J. Fluor. Chem. 86189

[39] Gyular G and Greenhow E J 1974 J. Therm. Anal. Calorim. 6 279

[40] Criado J M 1981 Thermochim. Acta 43111

[41] Málek J 1992 Thermochim. Acta 200257

[42] Zhang C T, Wang J K and Wang Y L 2005 Ind. Eng. Chem. Res. 447057

[43] Coats A W and Redfern J P 1964 Nature 20168 